\title{
Foreign elements in a clam shell: a clue to the history of marine pollution events
}

\author{
Lee-Shing Fang and Pouyan Shen \\ Institute of Marine Biology \\ and \\ Institute of Materials Science and Engineering, National Sun Yat-Sen University, Kaohsiung, Taiwan 800, Republic of China
}

\begin{abstract}
A new phenomenon of distribution of foreign elements in clam shells (maximum quantity at surface and along edges of the shell) is reported and interpreted. The new finding makes it possible to reconstruct the history of contamination in the waters surrounding the organism concerned. It further suggests inadequacy of previous techniques in using mollusk shells for measuring the degree of water pollution.
\end{abstract}

Bivalve shells have been shown to be useful in monitoring heavy-metal pollution in the marine environment; shell composition changes as a result of changing water chemistry (Bertine and Goldberg, 1972; Goldberg et al., 1978; Miramand et al., 1980). Apparently, shells provide more sensitive and more irreversible clues for monitoring changes in ambient heavy metals than the soft tissues (Miramand et al., 1980; Koide et al., 1982). We report here on the composition of metals and sulfur in the shell, and illustrate the usefulness of shell chemistry as a tool for determining the history of the chemical environment of the organism concerned.

Individuals of the clams Meretrix lusoria (Röding) were collected from a shallow-water culture farm near an estuary in southern Taiwan $\left(120^{\circ} \mathrm{E}, 23^{\circ} \mathrm{N}\right)$. This species inhabits sandy beaches exposed to air for a few hours during low tide. These clams are found in an anoxic environment with gray-to-black organic matter. Shell samples were first separated from living soft tissues, washed with distilled water, exposed to ultrasonic radiation for $2 \mathrm{~h}$ to remove possible foreign materials, and then air-dried prior to scanning electron microscopy (SEM). Shells of 3 to $4 \mathrm{~cm}$ in width which represent 8 mo to 1 yr of growth were used.

Point-count analyses by SEM (JSM 35-CF), operating at 15 to $25 \mathrm{KV}$, coupled with energy dispersive analysis of X-ray (EDAX) technique, were made on the outer surface, as well as on intermediate and inner layers exposed in the fractured clam shell. Sample size was estimated to be several microns. Occasionally, an electron beam was scanned on a specific area (e.g. $3 \times 3 \mu \mathrm{m}$ ) in order to control the measurements. The distance from hinge to the measuring spot was estimated on the magnified electron image of the shell. In the inner and intermediate layers only $\mathrm{Ca}$ was detected, $\mathrm{X}$-ray diffraction $\left(\mathrm{CuK}_{\alpha}\right)$ analysis indicated aragonite to be the major substance in the intermediate layer. Significant amounts of $\mathrm{Ca}, \mathrm{S}$ and $\mathrm{Fe}$, with minute amounts of $\mathrm{Cu}, \mathrm{Zn}, \mathrm{Cl}$ were detected in the outer layer (periostracum). The significant amounts of $\mathrm{Fe}$ and $\mathrm{S}$ on the shell are expected since the habitat of the clam, similar to other subtidal anoxic marine sediments, contains abundant amounts of soluble sulfide $\left(\mathrm{H}_{2} \mathrm{~S}\right.$ and $\mathrm{HS}^{-}$) and acid-labile sulfides (FeS) (Howarth and Giblin, 1983).

$\mathrm{Ca}, \mathrm{S}, \mathrm{Fe}, \mathrm{Cu}$ and $\mathrm{Zn}$ were analyzed next from the umbo to the posterior edge of the shell (following the growth direction), and the relative amounts of $\mathrm{S}, \mathrm{Fe}$, $\mathrm{Cu}$, and $\mathrm{Zn}$ over $\mathrm{Ca}$ were estimated from the EDAX peak height (i.e. counts). Ca was used as reference because it is the major constitutional element of the shell. Fig. 1 and 2 show a general trend of increasing $S$, $\mathrm{Fe}, \mathrm{Cu}$ and $\mathrm{Zn}$ towards the outer edge (younger portion) of the shell. This is in contrast to the previous concept, i.e. that pollutants accumulate with increasing age, which implies that the older portion should be richer in metals than the younger portion of the shell. Surface sorption processes are assumed to be responsible for the accumulation of metal pollutants in the shell (Miramand et al., 1980). Such assumption cannot be used to explain our data either. If surface sorption processes were the main operating mechanisms, we should expect a uniform distribution of for- 


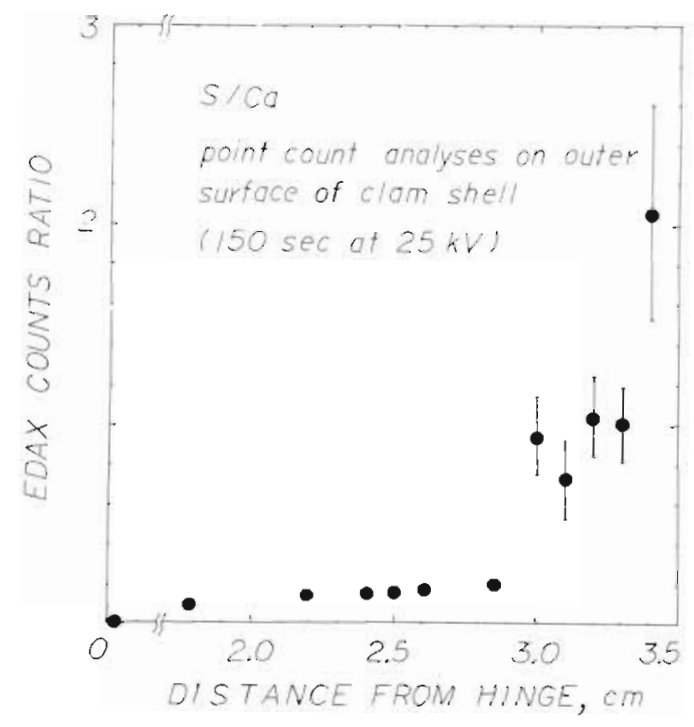

Fig. 1. EDAX count ratios of $\mathrm{S}$ over $\mathrm{Ca}$ in the outer layer of a clam shell (Meretrix lusoria) as a function of distance from the hinge. Averages from over 50 point counts obtained from 3 clam shells

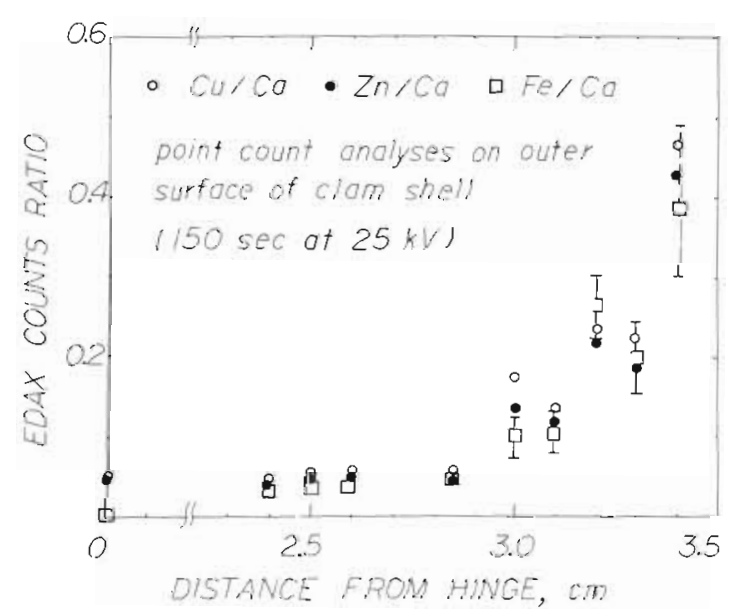

Fig. 2. EDAX count ratios of $\mathrm{Cu}, \mathrm{Zn}, \mathrm{Fe}$ over $\mathrm{Ca}$ in the outer layer of a clam shell (Meretrix lusoria) as a function of distance from the hinge. Standard deviations for $\mathrm{Cu}$ and $\mathrm{Zn}$ are of similar range than those for Fe

eign elements over most of the shell, except for a small decrease toward the growth edge.

The finding of increasing $\mathrm{S}, \mathrm{Fe}, \mathrm{Cu}, \mathrm{Zn}$ over $\mathrm{Ca}$ toward the edge of the shell leads us to assume the following mechanism for foreign element accumulation in clam shells: The carbonate exoskeleton may serve as receptacle for unwanted chemicals (Bertine and Goldberg, 1972), which are actively removed from the soft tissue and deposited mostly along the growing edge of the shell. The bound chemicals in the old parts of the shell will begin to leach out into the water, with a specific half-time up to several months (Guary and Fowler, 1981), e.g. approximately $100 \mathrm{~d}$ for $\mathrm{V}$ (Miramand et al., 1980), Zn (Young and Folsom, 1967),
Co (Van Weers, 1973), Hg (Fowler et al., 1978) and Se (Fowler and Benayoun, 1976). Such reasoning supports our data which show an increasing amount of $\mathrm{S}, \mathrm{Fe}, \mathrm{Cu}$ and $\mathrm{Zn}$ along the growth direction of the shell Moreover, since the quantity of foreign elements in the shell reflects the concentration of those elements in the surrounding water (Chow et al, 1976; Phillips, 1977), our findings can provide information about the history of ambient water chemistry. The residual amount of an element in the shell at any growth time can be measured with EDAX and the leaching-out rate or half time of the element can be determined (Miramand et al., 1980; Guary and Fowler, 1981). Therefore, by applying a simple calculation similar to that of radioisotope decay, the original quantity of an element fixed on the outer layer of the shell at any time of growth can be calculated. Since the original quantity is an index of the condition of the surrounding water, the whole pollution history can be reconstructed.

Our results, that the foreign elements accumulate on the outer surface of the shell and the amounts of $S, F e$, $\mathrm{Cu}$ and $\mathrm{Zn}$ decrease with age, call for precautions when using shells as a monitor for environmental pollution. Normally, the concentration of pollutants in the whole shell was used for estimating the degree of water pollution. Since we found that pollutants accumulated mostly on the surface and subsequently leach out as the shells grow, it is obvious that when aged clams with thick and big shells are analyzed for bulk composition, the degree of pollution may be considerably underestimated. This fact is worth noticing when bivalve shells of different ages or sizes are used in a long-term monitoring program. In other words, a decrease in the level of pollution measured might simply be an artifact due to the inadequacy of the method used. It should be cautioned, however, that our findings might pertain exclusively to clam shells which are aragonite based, and may not be true for shells made of calcite or other materials.

Acknowledgement. We are grateful to Professors F. S. Chia, C. W. Ong and D. Gan for critical reviews of the paper, and to Miss S. F. Chiou for preparing the manuscript.

\section{LITERATURE CITED}

Bertine, K. K., Goldberg, E. D. (1972). Trace elements in clams, mussels and shrimp. Limnol. Oceanogr. 17 (6): $877-884$

Chow, T J., Snyder, H. G., Synder, C. B. (1976). Mussels (Mytilus sp.) as an indicator of lead pollution. Sci. Total Environ. 6: 55-63

Fowler, S. W., Benayoun, G. (1976). Influence of environmental factors on selenium flux in two marine invertebrates. Mar. Biol. 37: 59-68

Fowler, S. W., Heyraud, M., La Rosa, J. (1978). Factors affect- 
ing methyl and inorganic mercury dynamics in mussel and shrimp. Mar. Biol. 46: 267-276

Goldberg, E. D., Bowen, V. T., Farrington, T. W., Harvey, G. Martin, J. H., Parker, P. L., Risebrough, R. W., Robertson, W., Schneider, E., Gamble, E. (1978). The mussel watch. Environ. Conserv. 5: 101-125

Guary, J. C., Fowler, S. W. (1981). Americium-241 and Plutonium-237 turnover in mussels (Mytilus galloprovincialis) living in field enclosures. Estuar. coast. Shelf Sci. 12: $193-203$

Howarth, R. W., Giblin, A. (1983). Sulfate reduction in the salt marshes at Sapelo Island, Georgia. Limnol. Oceanogr. 28 (1): 70-82

Koide, M., Lee, D. S., Goldberg, E. D. (1982). Metal and transuranic records in mussel shells, byssal threads and tissues. Estuar. coast. Shelf Sci. 15: 679-695
Miramand, P., Guary, J. C., Fowler, S. W. (1980). Vanadium transfer in the mussel Mytilus galloprovincialis. Mar. Biol. 56: $281-293$

Phillips, D. J. H. (1977). The use of biological indicator organisms to monitor trace metal pollution in marine and estuarine environments - a review. Environ. Pollut. 13: 281-317

Van Weers, A. W. (1973). Uptake and loss of ${ }^{65} \mathrm{Zn}$ and ${ }^{60} \mathrm{Co}$ by the mussel Mytilus edulis L. In: Radioactive contamination of the marine environment. International Atomic Energy Agency, Vienna, p. 385-401

Young, D. R., Folsom, T. R. (1967). Loss of ${ }^{65} \mathrm{Zn}$ from the California sea mussel Mytilus californianus. Biol. Bull. mar. biol. Lab., Woods Hole 133: 438-447

Accepted for printing on March 18, 1984 